\title{
A MULTI-DIMENSIONAL METHOD FOR EVALUATING A PRODUCT'S CONCEPTUAL SCHEMES
}

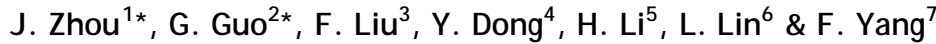 \\ ${ }^{1,3}$ Department of Management Science and Engineering post-doctoral station, \\ Chongqing University, P. R. China \\ ${ }^{1}$ ecozh@cqu.edu.cn \\ 2,4,5,6,7 Department of Mechanical Engineering, \\ Chongqing University, P.R. China \\ 2qczx@cqu.edu.cn
}

\begin{abstract}
The use of conceptual scheme evaluation is a key step in the development of new products. In this paper, a multi-dimensional evaluation method that involves subjective evaluation, eye-tracking, and product image evaluation is established. In this study, subjective evaluation is used to test customers' initial reactions to conceptual schemes, and eyetracking is used to highlight the features of conceptual schemes that are most attractive to customers. With the help of Kansei engineering, the most attractive features of a particular product are described and clarified from the product image evaluation. This multidimensional method can be applied not only in screening conceptual schemes, but also in exploring the reasons and suggestions for product improvement. The method was assessed in this study through a case study evaluation of conceptual design schemes for a mobile phone.
\end{abstract}

\section{OPSOMMING}

Die gebruik van konseptuele skema beoordeling is ' $n$ sleutel stap in die ontwikkel van nuwe produkte. 'n Multidimensionele beoordelingsmetode, wat subjektiewe beoordeling, die volg van oog beweging en produk beeld beoordeling behels, is ontwikkel. Subjektiewe beoordeling word gebruik om kliënte se aanvanklike reaksies op konseptuele skemas te toets. Die volg van oog beweging word gebruik om die mees aantreklike eienskappe van konseptuele skemas uit te lig. Met die hulp van Kansei ingenieurswese word die mees aantreklike eienskappe van ' $n$ spesifieke produk beskryf en duidelik gemaak vanuit die produk beeld beoordeling. Hierdie multidimensionele metode kan ook toegepas word in die motiverings en aanbevelings vir produk verbetering. Dié metode is beoordeel deur ' $n$ gevallestudie van konseptuele ontwerpskemas van ' $n$ selfoon.

\footnotetext{
${ }^{1}$ A post-doctoral scholar in the Department of Management Science and Engineering, Chongqing University, P. R. China.

* Corresponding authors
} 


\section{$1 \quad$ INTRODUCTION}

Product innovation is one of the principal ways to improve the competitiveness of enterprises in manufacturing markets [1]. In that context, product design aims to attract the attention of consumers and stimulate their desire to buy the product $[2,3]$. For this reason, product design has gained much interest in industry and academia. The business environment is fast-changing, and nowadays the conceptual design of a product focuses on production creation methods and design strategies [4].

When designing a new product, the reactions of consumers are evaluated using tests: this assists in finding the most suitable product concept prior to accessing the market. Various forms of presentation (e.g., descriptions, drawings, or prototypes) are used to demonstrate product concepts. Generally, such evaluations aim to select or optimise product concepts according to the preferences of particular consumers or stakeholders. Typically, screening and optimising concepts need to be considered when evaluating a product concept, together with the decision about whether or not to continue with the product design [5].

Concept design is a key process in the development and innovation of a new product. Testing and evaluating the concept is also vital in order to judge the likelihood of a new product being successful, and it is therefore applied before marketing. The results of the evaluation can also provide an insight into the possible methods needed to optimise a particular product. Unfortunately, some small-scale manufacturing firms fail to reap the benefits of good design practices, because they lack the ability to employ scientific testing and evaluation methods [6].

This study aims to evaluate a set of conceptual schemes, using a multi-dimensional method that, this study argues, is able to deliver more effective and authentic evaluation results. The paper is presented as follows: a literature review is followed by an introduction to the multi-dimensional method. This is followed by the presentation of the methodology used and the process involved in the multi-dimensional method. A case study based on a mobile phone design is evaluated using this method. Finally, the results are demonstrated and discussed.

\section{LITERATURE REVIEW}

Many traditional methods are used to evaluate the design concept of a new product, such as questionnaire surveys for experts and the subjective evaluation of customers and target customer groups. Other specific methods have been used, such as systematic analysis, value engineering, physical programming, analytic hierarchy processes (AHP), and fuzzy theory methodology. In previous studies, Mahmood and Sullivan [7] applied expert-based surveys to screen ideas for new products, whereas Vanegas and Labib [8] proposed an aggregate profile of performance to compare the overall performance of candidate designs. in another study, a fuzzy AHP method was applied to exclude a set of conceptual design alternatives, whereby a predetermined constant value was obtained under certain conditions, and scores (or weights) lower than this value were not considered [9]. Evans et al. [10] have concluded that there are limitations to the modelling capability of commercial haptic feedback technology, and thus it may not be effective enough to make a significant contribution within industrial design practice. Mugge et al. [11] developed a 20-item scale that aimed to assess a product's personality based on its appearance, whereas Sarkar and Chakrabarti [12] proposed a new method for assessing the innovation of products to judge their novelty and usefulness. In a different study, an online affordance evaluation model was established to evaluate the practicability of a product [13]. Quantitative analysis has been carried out in evaluation processes, using methods such as AHP [9], fuzzy theory, and simulation analysis[14]. These methods aim to eliminate the subjective impact of evaluators as much as possible. These methods are limited, however, because they are not able to explain why a particular conceptual scheme is preferred over another, nor the reasons behind the suggestions for improvements to a particular product. For these reasons, 
the results of these evaluation methods are considered to be insufficiently direct and specific.

With the developments made in technology, and the standard of living rising in certain countries, product design has now become focused on the aesthetic value of a product. Product design now not only emphasises the product's properties and functions, but also incorporates the user's feelings and experiences [15]. It is now considered vital to evaluate whether a new product's conceptual design is able to appeal emotionally to consumers $[16,17]$. In addition, the development of products has shifted from being manufacturingcentred to being user-centred. Consumers today no longer seek only one feature in a product, but instead desire multiple features to satisfy their physiological and psychological needs (such as function, psychology, emotion, and experience) [16]. However, there are bound to be many differences between the perceptions of the designer and those of the user, even if they have the same objectives. Additionally, their understanding and interpretation of words used for a particular image may differ [18]. It is therefore considered important to listen to the voices of customers in product optimisation and process innovation [19]. Xu et al. [20] proposed an analytical Kano (A-Kano) model to analyse customer needs and thus to allow customers' preferences to be incorporated into product design. Lee and Chang [3] collected 'the wisdom of crowds' via the internet; from their results, customers' affective responses were explored, and they were able to present an innovative simulation system for designers. In addition, it has been suggested that personas should be incorporated into design approaches [21]. Furthermore, Park [22] developed a knowledge management system to enable users to express their own ideas on product design.

In general, evaluation methodology involves the use of both qualitative and quantitative methods. Qualitative indicators can also be quantified to deliver evaluation results with better validity and reliability. Qualitative methods, however, mainly depend on the subjective evaluation results of one dimension, and because there is inevitably an interaction between a subject and the interviewer, the responses and activities of subjects can be influenced by the speech, behaviour, facial expressions, and even the expectations of the interviewer. In addition, when several subjects are involved, it is more difficult to exclude the impact of one person on another. Thus, evaluation results can never be entirely objective. To address the subjectivity and arbitrariness of subjects, the reliability of evaluation methods also needs to be verified and improved.

In relation to this, an eye movement apparatus was applied to test interaction and usability; it was discovered that the users' interests, habits, and characteristics can be revealed using the results of eye movement [23-25]. Eye movement apparatus is seen as an efficient tool for evaluating conceptual designs, and could compensate for the deficiency of existing tests. In a previous study, an eye-tracking-based method was solely applied to evaluate the design of a mobile phone, and showed a connection between gaze, product attitude, and preference. Although using a single dimensional method was effective, it was still not enough to demonstrate the comprehensive perception of consumers [26]. In short, the conceptual design of a new product should also be evaluated using consumers' perceptions: this could assist designers to gain a better understanding of the emotional cognition of consumers, and to grasp consumers' intuitive feelings and real expectations more accurately. The results would therefore help to optimise a product's design.

\section{RESEARCH METHODOLOGY}

\subsection{Subjective evaluation methodology}

The design scheme is scored by the subject according to the degree of satisfaction experienced by the subject. It is then possible to calculate the average evaluation score for each optional scheme. By scoring and sorting the optional schemes subjectively, an overall degree of satisfaction can be obtained, and the scheme that gains the highest satisfaction 
score can then be selected for further evaluation. If the satisfaction degree of all schemes is low, the optional schemes require re-designing.

The satisfaction degree of optional schemes is classified by using the following scores:

- A score in the interval of 80-100 implies a high degree of satisfaction: follow-up tests would immediately be performed on schemes scoring in this range, including validation and further optimisation.

- Scores in the range of 60-80 show that there is a general degree of satisfaction with the scheme, and that a further evaluation is required using both objective and subjective product perception image tests. After evaluating the concerns and causes, these design schemes would then be greatly modified.

- If the score is in the range of $0-60$, the satisfaction degree of the scheme is considered to be low, and the scheme requires re-designing. However, because of the cost control involved in research and product development, these schemes would be excluded from any subsequent tests.

Optional schemes are evaluated using the distribution of scores. The satisfaction threshold of subjective evaluation is set as a, and the overall score level can be calculated as follows:

$$
\eta=k / m,(0 \leq \eta \leq 1)
$$

where $\mathrm{k}$ is the number of schemes with evaluation scores higher than $a$, and $m$ is the total number of optional schemes.

If $\eta$ is close to 1 , it indicates that the conceptual design is successful. In contrast, if $\eta$ is close to 0 , it means that the conceptual design is low and therefore that problems need to be identified and the product re-designed.

\subsection{Objective evaluation methodology based on eye-tracking}

An eye tracker is an apparatus commonly used to measure eye movements. It records three types of eye movements: fixations, smooth pursuits, and saccades. These eye movements can help gain an insight into the significant localisation of visual attention. Based on signal characteristics and underlying neural circuitry, the three types of eye movement are recorded by a linear, time-invariant system. Eye fixation, which implies a stable retina over a stationary object, corresponds to a person's desire, because it involves their staring at an object of interest [27]. A recorded 'hotspot' represents the duration of eye fixation: a 'redder' hotspot indicates a longer fixation. A hotspot is defined as a point with a large saliency value on a saliency map [28].

The test materials (evaluation samples) used in this study were the optional schemes of a design concept for a new product (Figure 1). All the schemes were shown to a subject. The eye tracker recorded the sight trajectory, pupil zoom, and blink. The relationship between the test materials and a person's eye movements was then analysed to evaluate psychological reactions and user preferences.

After establishing a test environment, the test materials were shown to the subjects. The eye tracker was applied to obtain user preferences and key influencing elements. To ensure the accuracy of the test, the subject was asked to consider various key elements of the product, and the principle of random positioning was considered. It was then possible to apply the subjective evaluation results obtained to evaluate and optimise the scheme further. 


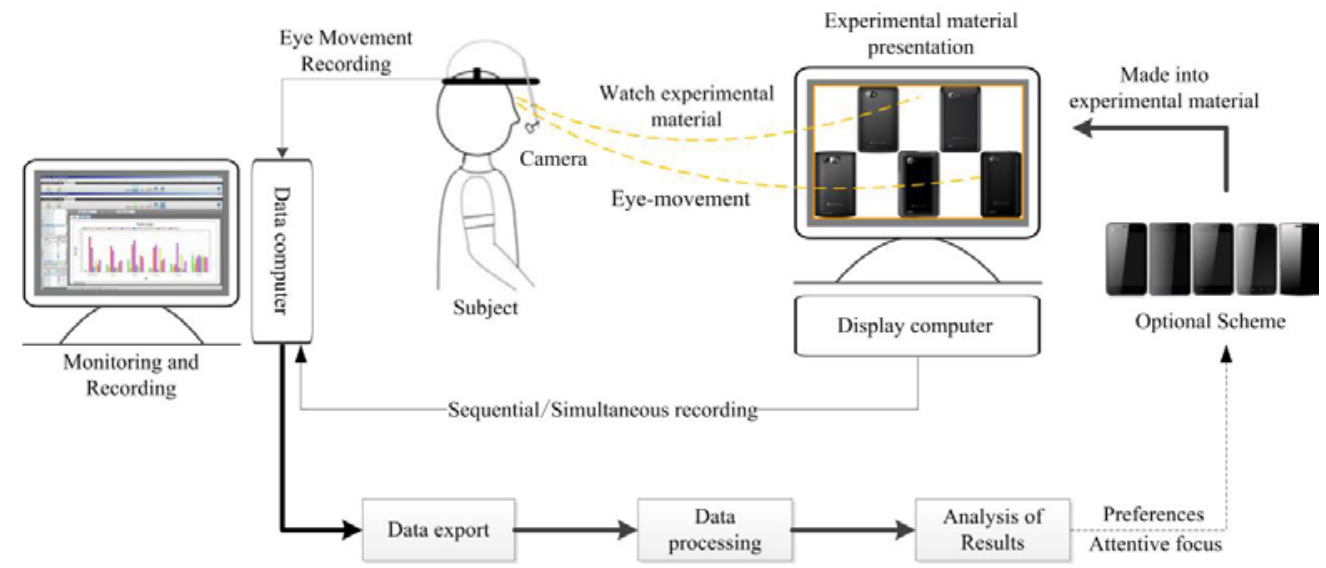

Figure: 1 Objective evaluation method, based on eye movements, to test a new product concept

\subsection{Perceptual image methodology based on Kansei engineering}

Kansei engineering is a method used to translate consumers' feelings and images into design elements [29]. This method is considered to be an advanced technology for use in product development to express customer demand for a design. As a customer-oriented ergonomic technology, Kansei engineering has been applied in product development. This technology, which is based on the human cognitive model, could help in designing a satisfying product for each user [30].

During this study a conceptual design scheme was presented to subjects (Figure 2) using stimulation factors that include shape, colour, and materials. A perceptual image of a product is formed in the mind of each subject, based on their existing experience and personal thoughts. This perceptual image can then be classified using the product image scale. From this, the features of the optional schemes can be better understood and evaluated.

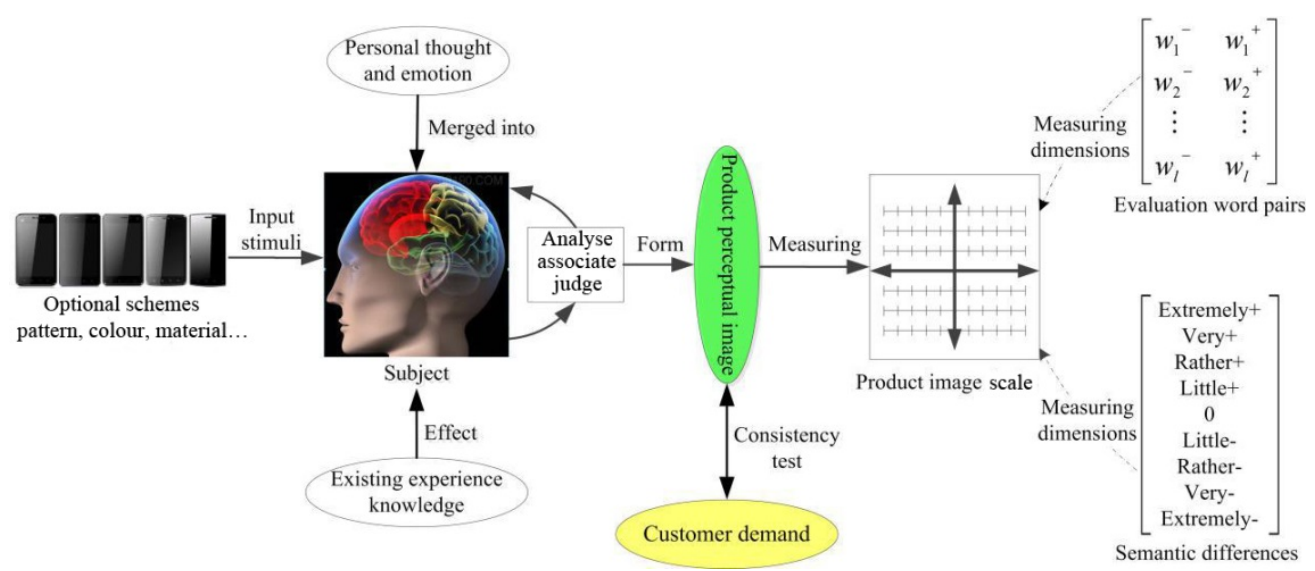

Figure 2: Product image cognition and testing evaluation model

The specific processes involved were as follows:

First, the interviewers collected several adjectives that describe the product's image, from sources such as product magazines, advertisements, relevant websites, and dictionaries. The antonyms of these adjectives were then provided to form a word pair. The target customers and professionals were invited to judge whether or not the word was appropriate for use in describing the materials. Similar or seldom-used adjectives were removed. After 
screening, a formal image evaluation word set $W=\left\{w_{1}, w_{2}, \ldots, w_{l}\right\}$ was established, where $w_{i}$ represented one dimension of an image evaluation described by two words with opposite meanings ( $w_{i}^{-}$and $w_{i}^{+}$), and $l$ was the image evaluation dimension. Considering the description of the product's features and the measurement's operability, the recommended number of $l$ was between 10 and 30 [31].

To differentiate degrees of psychological change, the words "extremely", "very", "rather", and "little" were used. Based on semantic differences, a comment set with seven, nine, or eleven levels was established, in which neutral points 'zero' meant 'no sense' on this dimension. The test questionnaires on a product's perceptual image were prepared, based on the imagery of word pairs and a comment set. The product's perceptual image was evaluated using scores from the subjects. Every single optional scheme was scored in each evaluation dimension, and the mean score of each optional scheme was calculated for the imagery word pairs of one dimension. Each word pair involved cognitive thought, and presented the psychological experience of a subject.

Thus, the words selected to describe optimum schemes, which were obtained from the former test, were also able to explain how a product design could perform better. The test also analysed the degree to which the perceptual image of each optional scheme matched the customers' demands. In addition, the optimum scheme was able to be improved in accordance with the characteristics of other schemes that were more consistent with customers' demands.

Through subjective and objective evaluations, the overall and detailed preferences of particular schemes can be obtained, and then incorporated into subsequent conceptual designs. With analysis of the product's perceptual image, the strengths and weaknesses of the schemes can also be identified, and such results can be used to guide further scheme improvements.

\subsection{Processes involved in using the multi-dimensional evaluation method in relation to a product's conceptual schemes}

For the process of scheme screening and evaluation, the objects presented to the subjects were generally in the format of a design sketch, effect drawing, or physical model. The innovation employed in the product design was mainly described visually, and the selection and evaluation of the new products were demonstrated using description. As this method is subjective or ambiguous, to some degree, it would be too risky to select and invest in a final scheme using this process. The purpose of this evaluation, therefore, is to identify the degree of objective satisfaction experienced by the target customers, in relation to the design scheme. In addition, any recommendations for optimising the product design could be obtained.

In this study, subjective evaluation, eye tracking, and Kansei engineering were integrated in the multi-dimensional evaluation method. Subjective evaluation helps test the initial reactions of customers to the conceptual schemes. The results of eye tracking are then used to explore to highlight features of the scheme that capture the attention of the customers. Finally, these identified features are described and clarified using Kansei engineering. Thus, it is not only possible to apply the multi-dimensional method to screen conceptual schemes, but also to explore recommendations for product improvement. In this study, the evaluation is broken down into three categories: "satisfied or not", "what makes you feel satisfied", and "why it is satisfactory". These problems were resolved one by one and step by step. By using this multi-dimensional method, a greater degree of accuracy and objectivity can be achieved when evaluating conceptual design schemes.

After demand acquisition, demand conversion, and conceptual design, tests on a selection of optional conceptual schemes for new products were conducted (Figure 3). For each 
optional scheme, three tests were conducted: subjective evaluation, recording of eye movements, and a Kansei engineering-based perceptual image test.

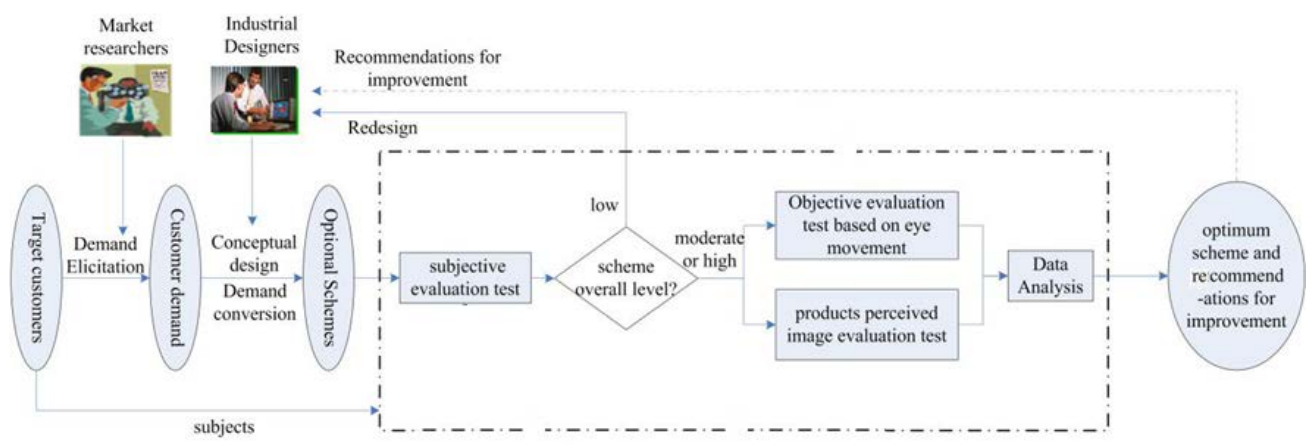

Figure 3: Process of multi-dimensional evaluation method used for conceptual schemes

The three evaluation steps mentioned above were carried out one by one with mutual authentication. The method not only evaluated and selected the optional conceptual design schemes for new products, but also identified those features of a particular product that interested customers, in addition to the perceptual image. Furthermore, the consistency and validity of the test results were verified from different dimensions. The comprehensive information obtained for each optional scheme could therefore assist in scheme optimisation.

\section{CASE STUDY: EVALUATION OF A MOBILE PHONE'S DESIGN SCHEMES USING THE MULTI-DIMENSIONAL EVALUATION METHOD FOR CONCEPTUAL SCHEMES}

\subsection{Subject recruitment}

Subjects were screened based on the product orientation, characteristics of the target customer group (such as age, gender, and income level), and test constraints (e.g., perfect vision was required). Thirty subjects $[32,33]$ were selected out of 56 college student volunteers, using open recruitment (22 males and eight females aged between 19 and 27). All of the subjects were open to the concept of buying a smart phone, and all would pay a price of approximately 1,500 Chinese Yuan (about ZAR 2,750) for that phone.

\subsection{Test materials}

For the case study, five optional schemes for the conceptual design of a mobile phone were provided by one company. This phone was proposed as being "an intelligent machine costing only 1,000 Chinese Yuan (about ZAR 1,500)". The target customers were young users aged between 18 and 30. The product was expected to reflect the following attributes: to have a unique personality, and to be fashionable yet simple and portable. After several rounds of design elimination, five optional schemes eventually remained: these were then presented in the form of pictures showing the front, back, left, right, top, and bottom of the phone (Figure 4). 


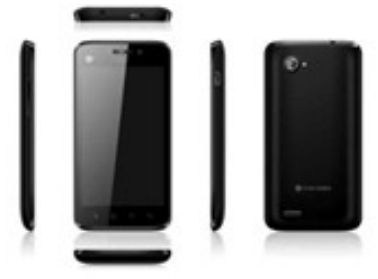

Scheme 1

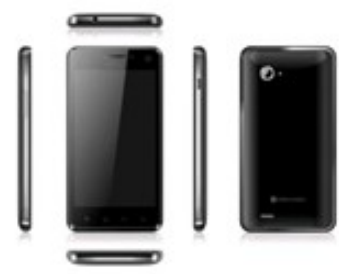

Scheme 3

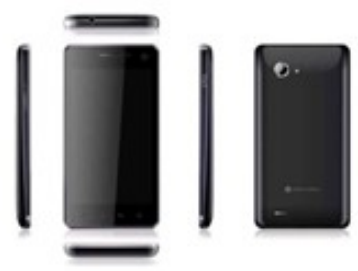

Scheme 2

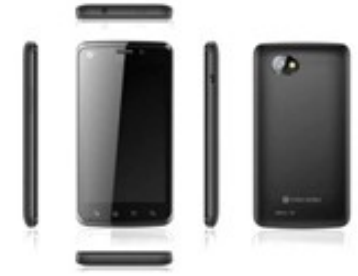

Scheme 4

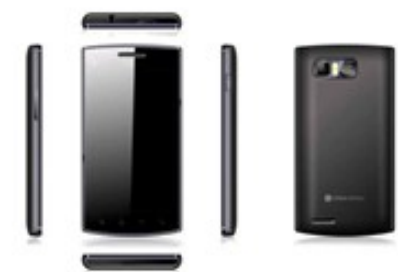

Scheme 5

Figure 4: Conceptual design schemes of products

\subsubsection{Subjective evaluation materials}

Subjective evaluation questionnaires consisted mainly of multiple-choice questions and sorting and ranking questions. Parts of the items were shown, as depicted in Figure 5.

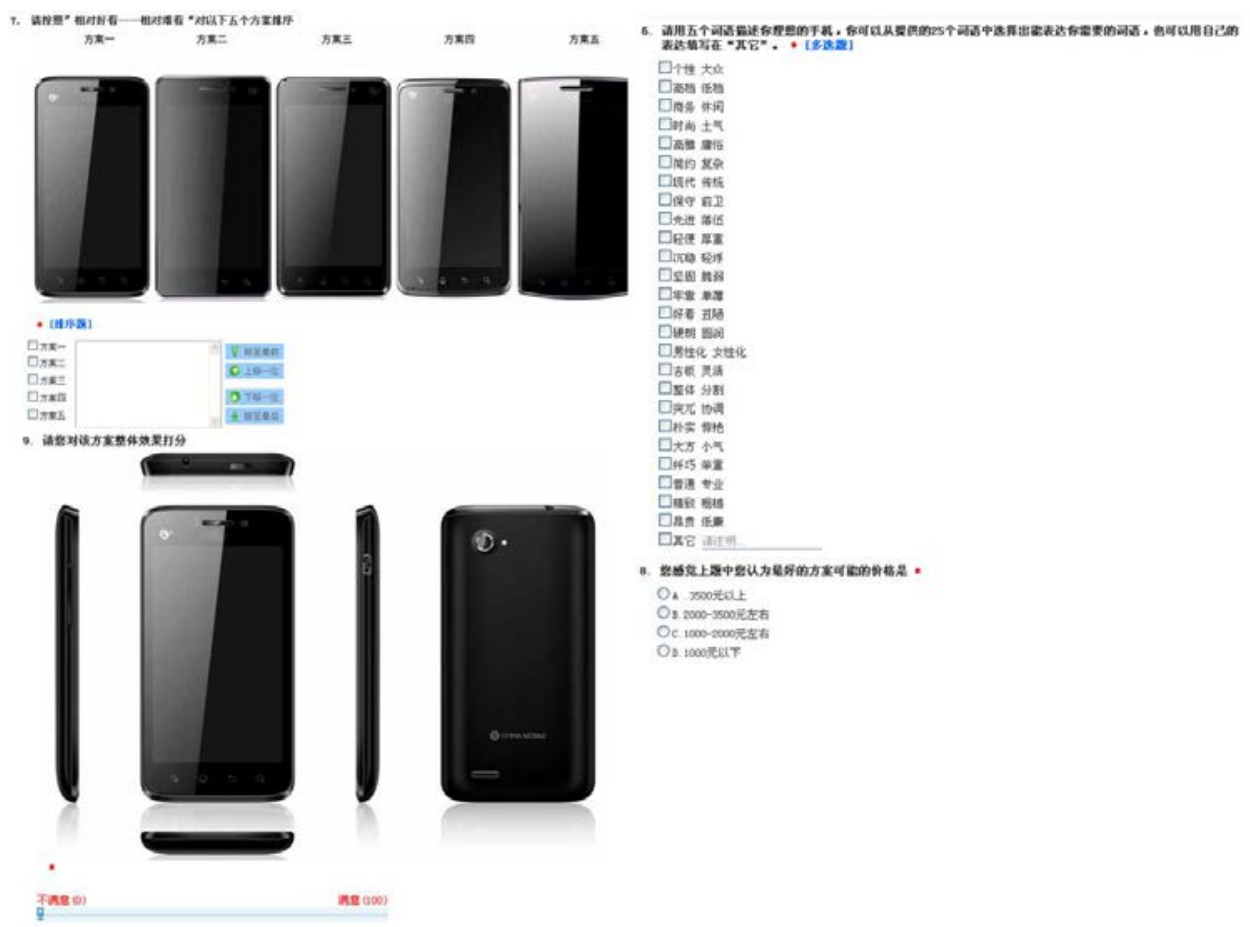

Figure 5: Subjective evaluation materials

\subsubsection{Objective evaluation materials}

The optional schemes were randomly presented to avoid any biases related to position, placement, and sequence. For the five optional schemes presented, the displayed contents 
were the front, back, corners, earpieces, and cameras of the phone. This was done with the aim of testing the specialised shape and layout of the product. The experimental materials were presented in the form of pictures in a BMP format at $400 \times 300$ pixels, on a flat 17 inch monitor with a resolution of $800 \times 600$ pixels. The objective evaluation materials used to test eye movements are shown in Figure 6.

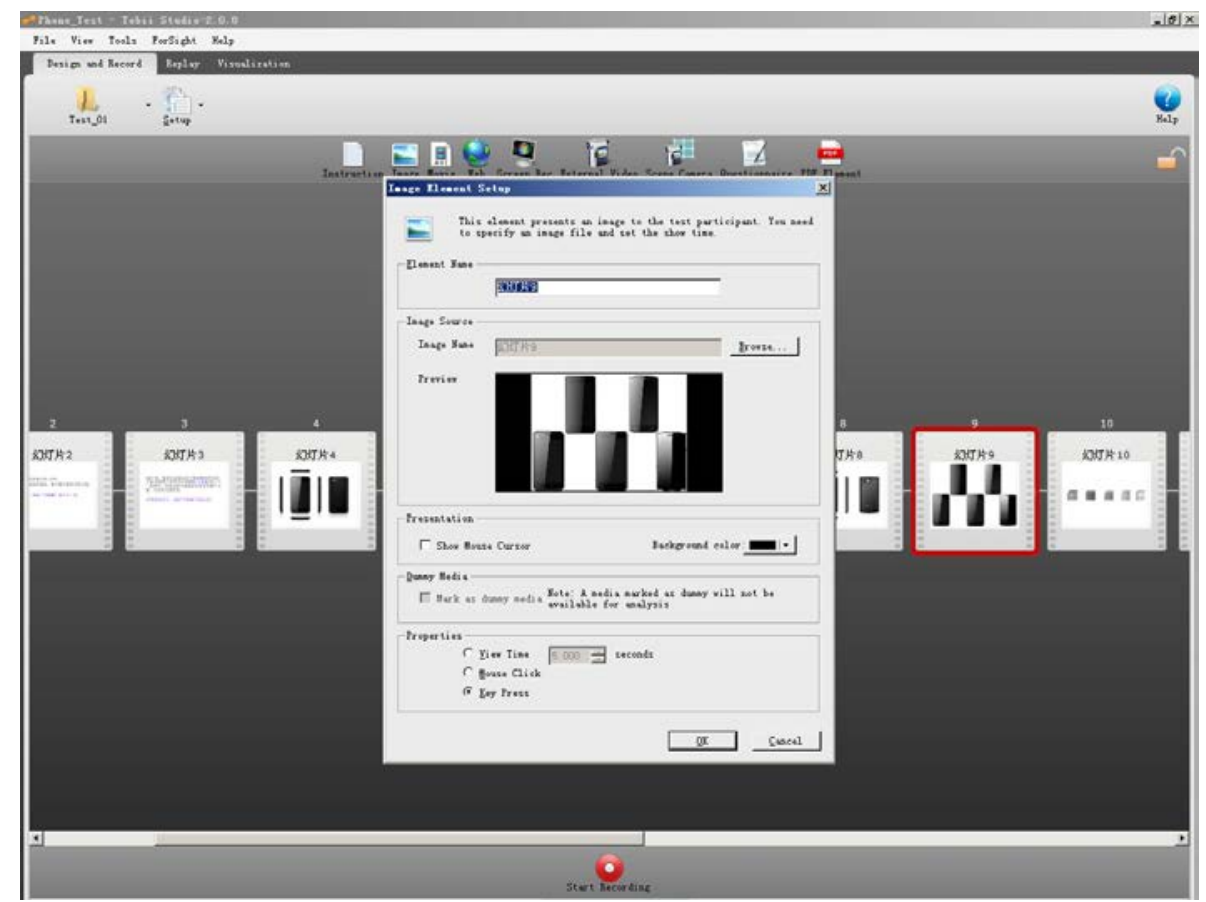

Figure 6: Objective evaluation materials for testing eye movement

\subsubsection{Product image evaluation materials}

Eighty-nine words were collected that described the phone in relation to the corresponding images presented. The words were collected using subject interviews, mobile advertisements, forums, and other related documentation. Any words with a meaning similar to another word were removed. Antonyms of these adjectives were found and paired, creating 42 word pairs. These word pairs were filtered by the target customer group and professional designers, and ultimately 25 pairs of adjectives were screened. The perceptual image evaluating questionnaire was compiled using a collection of comments with 11 levels of semantic difference.

\subsection{Experimental procedures}

In this study, the subjective evaluation questionnaires and the product perceptual image questionnaires were produced and published via the online survey website www.sojump.com. The questionnaires were completed by the subjects and submitted online. Eye movement tests were performed at the Key Laboratory of Cognition and Personality of the Ministry of Education at Southwest University. The main sites used for the experiment are shown in Figures 7 and 8. 


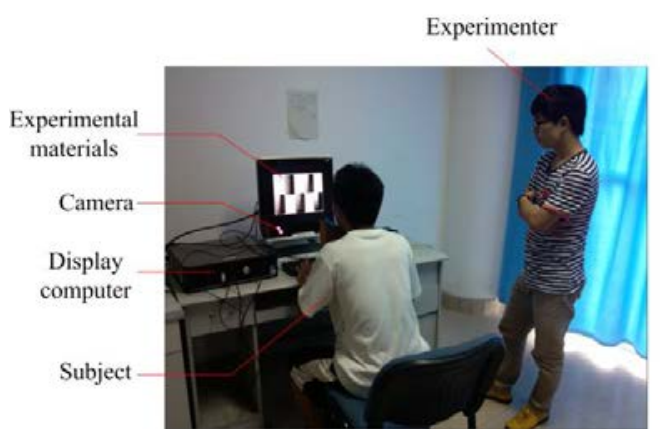

Figure 7: Eye movement test

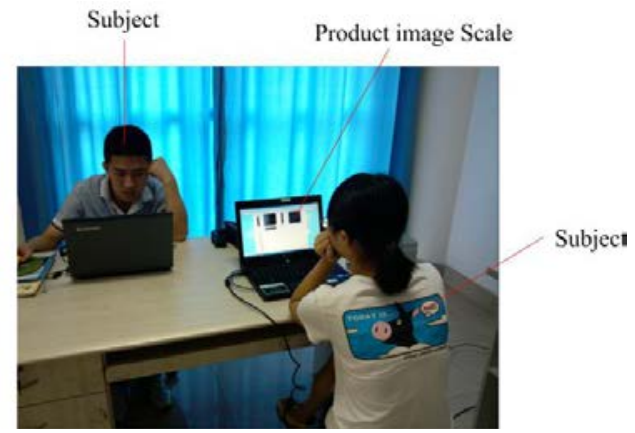

Figure 8: Subjective and perceptual image tests

\section{RESULTS}

\subsection{Analysis of subjective evaluation data}

Subjective evaluation data, as shown in Table 1, was obtained from the above tests.

Table 1: Subjective evaluation data

\begin{tabular}{|c|c|c|c|c|c|}
\hline Subjective evaluation & $\begin{array}{c}\text { Score of } \\
S_{1}\end{array}$ & $\begin{array}{c}\text { Score of } \\
S_{2}\end{array}$ & Score of $S_{3}$ & Score of $S_{4}$ & Score of $S_{5}$ \\
\hline Average score & 76.57 & 77.27 & 77.67 & 72.17 & 64.97 \\
\hline
\end{tabular}

Note: represents scheme i

According to the evaluation results, the highest rank was observed for Scheme 3, followed by Scheme 2. The lowest score was obtained for Scheme 5.

Set $a=60, k=5$, and $\eta=1$. This indicates that in the first round, the overall satisfaction degree in relation to the conceptual design schemes was 'medium'. Considerable product improvement is therefore necessary.

\subsection{Analysis of objective evaluation data}

The hotspot map of eye movement was obtained for each optional scheme. The focus of all the subjects was consistent for all schemes: the focused centres were located mainly on the front earpiece, camera, logo, and the side (Figure 9). 


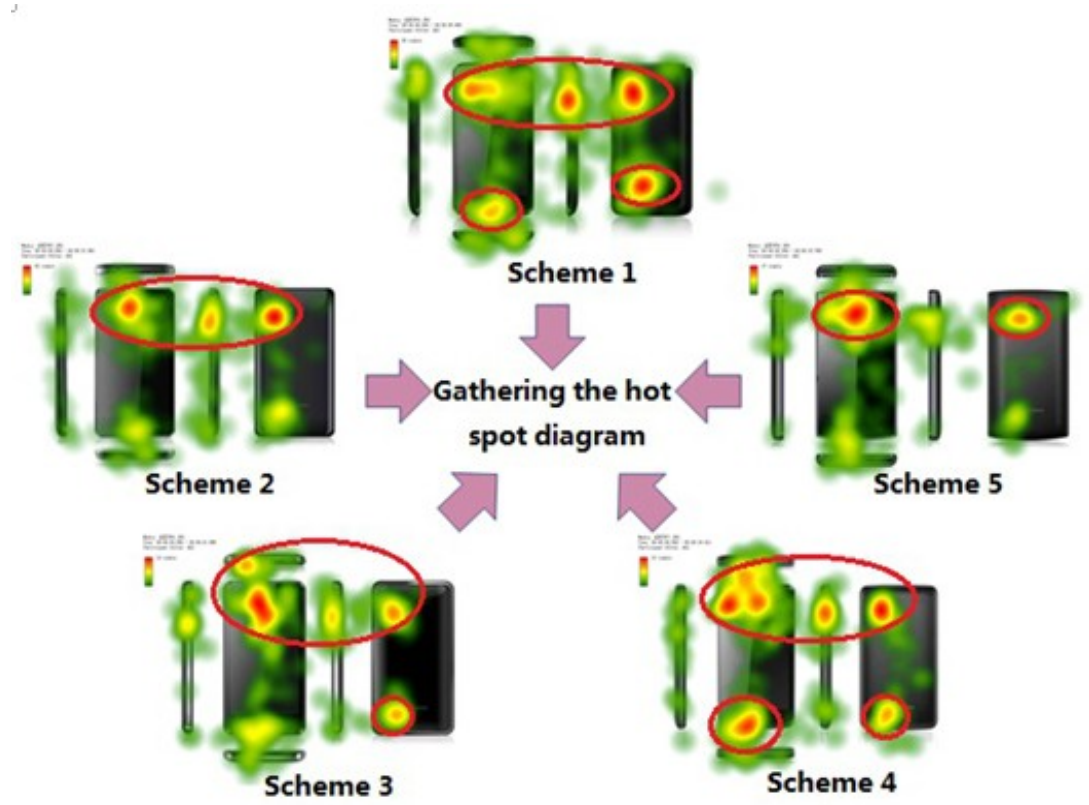

Figure 9: Analysis of hotspot map in the testing of eye movement

Comparing the focus in these schemes, the common attractive features extracted were the earpiece and camera. These thus became the new visual stimulus presented to the subjects (Figure 10).

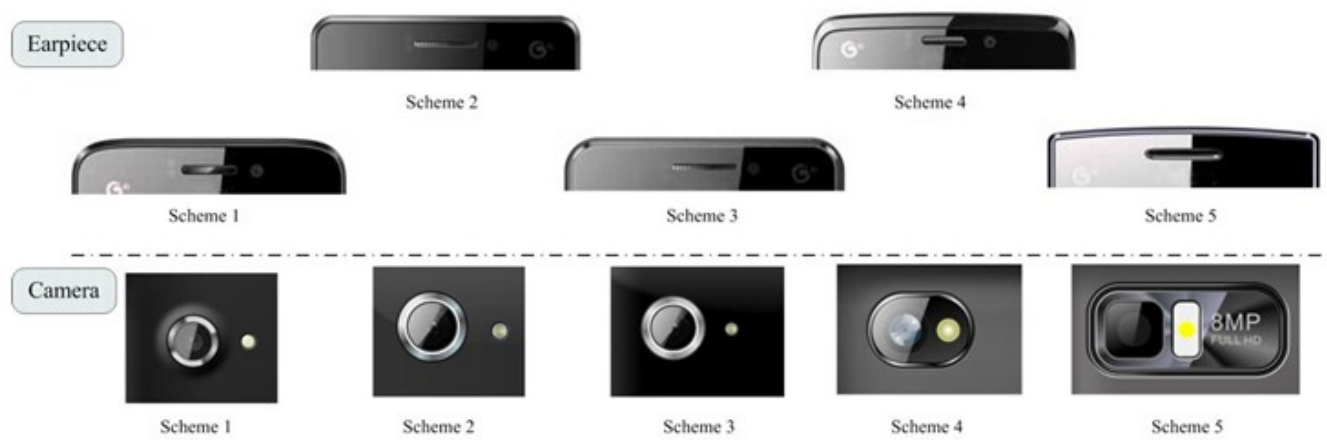

Figure 10: Schemes for the appearance of earpiece and camera

Eye movement data was analysed, based mainly on the length of time fixated on the earpiece and camera (Table 2). It could be ascertained that the attributes most favoured by subjects were the slim earpiece in Scheme 3 and the camera in Scheme 5.

Table 2: Comparative analysis of subjects' focus

\begin{tabular}{|l|c|c|c|c|c|}
\hline Fixation length(s) & $S_{1}$ & $S_{2}$ & $S_{3}$ & $S_{4}$ & $S_{5}$ \\
\hline Earpiece & $\mathbf{0 . 5 1}$ & $\mathbf{0 . 6 5}$ & $\mathbf{0 . 9 5}$ & $\mathbf{0 . 7 5}$ & $\mathbf{0 . 7 1}$ \\
\hline Camera & $\mathbf{0 . 7 3}$ & $\mathbf{0 . 9 8}$ & $\mathbf{1 . 4}$ & $\mathbf{0 . 8 5}$ & $\mathbf{1 . 7 8}$ \\
\hline
\end{tabular}

\subsection{Analysis of evaluation data for product's perceptual image}

The evaluation results for the product's perceptual image tests are shown in Figure 11. The initial goals of the product's conceptual design should take into account personality, fashion, simplicity, and portability. These goals were reflected, to a certain degree, in the 
five schemes, although not all the targets were fully reached. In particular, the problem of 'lack of personality' required further validation using subjective evaluation, and should therefore be considered in relation to further improvements required by the conceptual design.

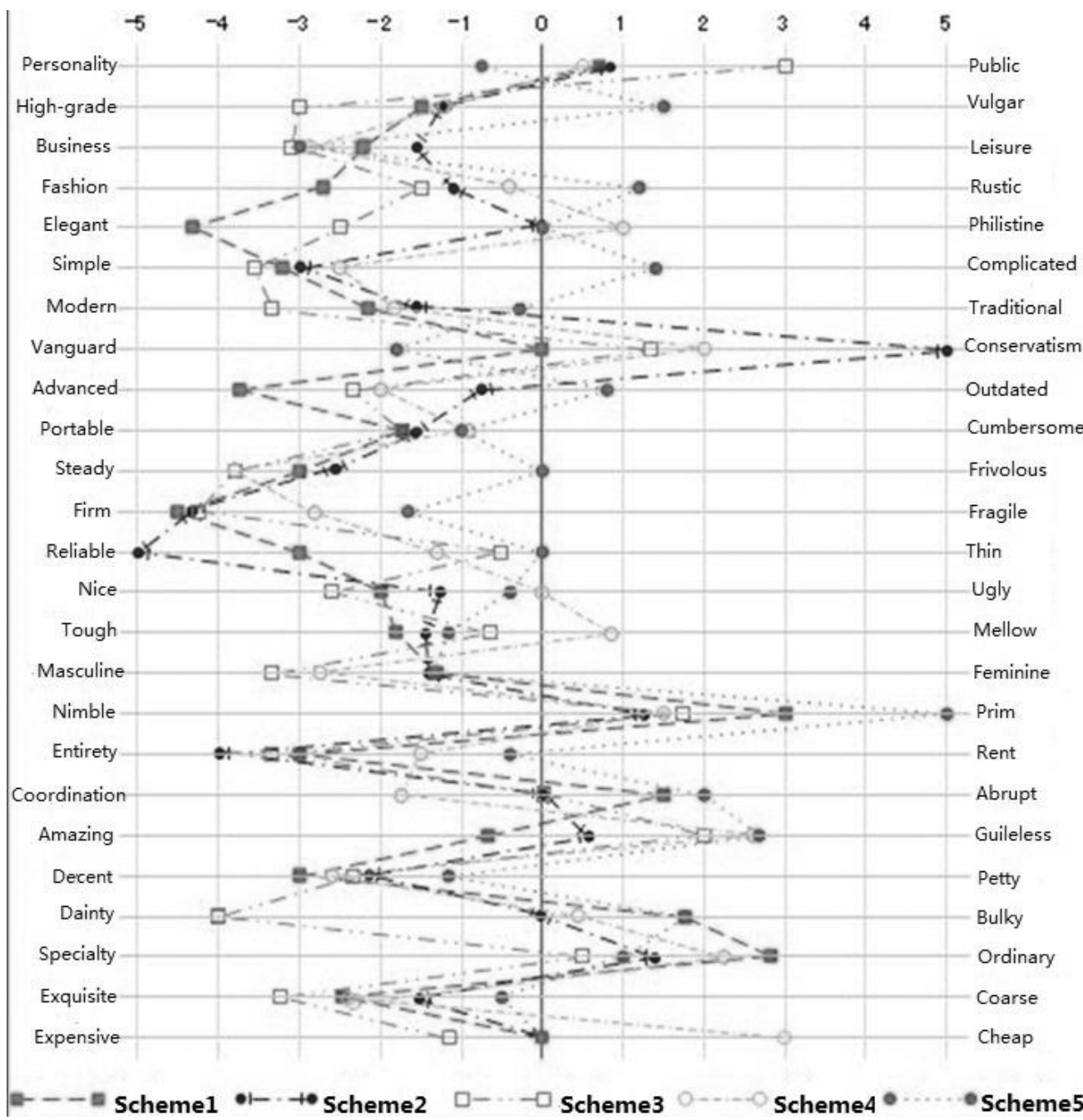

Figure 11: Evaluation of perceptual image of product

\subsection{Consistency analysis of evaluation data}

To verify the effectiveness of the evaluation, the consistency of the results of the subjective and objective evaluation was analysed (Table 3).

This showed that the evaluation results were generally the same, thus confirming that the evaluation method was reliable. An inconsistent ranking result was discovered, however, and this was acknowledged as being an unsolved problem within the method used. Analysis using greater accuracy and further judgement is therefore required. Relevant issues to be resolved include the following:

1. Subjects did not belong to the target customer group;

2. Subjects did not fully understand the requirements of the questions;

3. The position effect was not considered for the experimental materials; and 
4. There was a conflict or contradiction between the subjects' subjective thoughts and inner thoughts. Follow-up interviews are therefore required to explore the reasoning of the subjects.

Table 3: Consistency check of subjective and objective evaluation

\begin{tabular}{|c|c|c|c|}
\hline & Subjective & Objective & Consistency \\
\hline$S_{1-} S_{2}$ & $S_{2}>S_{1}$ & $S_{2}>S_{1}$ & consistent \\
\hline$S_{1-} S_{3}$ & $S_{3}>S_{1}$ & $S_{3}>S_{1}$ & consistent \\
\hline$S_{1-} S_{4}$ & $S_{1} S_{4}$ & $S_{4}>S_{1}$ & inconsistent \\
\hline$S_{1-} S_{5}$ & $S_{1>} S_{5}$ & $S_{5}>S_{1}$ & inconsistent \\
\hline$S_{2} S_{3}$ & $S_{3}>S_{2}$ & $S_{3}>S_{2}$ & consistent \\
\hline$S_{2} S_{4}$ & $S_{2}>S_{4}$ & $S_{2}>S_{4}$ & consistent \\
\hline$S_{2} S_{5}$ & $S_{2}>S_{5}$ & $S_{2}>S_{5}$ & consistent \\
\hline$S_{3} S_{4}$ & $S_{3}>S_{4}$ & $S_{3}>S_{4}$ & consistent \\
\hline$S_{3} S_{5}$ & $S_{3}>S_{5}$ & $S_{3}>S_{5}$ & consistent \\
\hline$S_{4-} S_{5}$ & $S_{4} S_{5}$ & $S_{4} S_{5}$ & consistent \\
\hline
\end{tabular}

This study used an online questionnaire and eye movement test, and succeeded in performing an experiment to evaluate the conceptual design for a smart phone. According to comprehensive analysis of the experimental data, it was found that Scheme 3 was optimal: it was considered to be simple and elegant, but lacking personality. However, this deficiency could be addressed using the features from Scheme 5. If Scheme 3 were revised using the camera from Scheme 5, a satisfactory result would be achieved. This study demonstrates how the results from the evaluation of the schemes can help one to select an optimum design scheme. In addition, the results could be used to explore a specific revision proposal. It is therefore concluded that the multi-dimensional method is a powerful tool for evaluating future designs and optimising these products according to customers' preferences.

\section{CONCLUSIONS AND RECOMMENDATIONS}

An important component of product design and decision-making includes determining the users' responses to the product and its schemes, and ensuring the objectivity and reliability of the research findings. Such insights can be obtained if the technology is available. If direct insights and observations are not available due to technical limitations, traditional research methods such as questionnaires, interviews, and seminars can be used. These traditional research methods do, however, have certain limitations: they depend mostly on the subjective reports of the research subjects; and for various reasons, the research subjects may not be able to express their views clearly, or may be unwilling to state their true opinions, or may not even realise the existence of certain implicit views.

In this study, we introduced an evaluation method using eye movement testing that can objectively present the realistic reactions of the subjects tested. Through a combination of subjective and objective methods, different technical methods were tested for consistency, and to ensure the effectiveness of the tests and reliability of the results. In addition, the image scale method was used to measure and analyse the subject's psychological reactions to product images, thereby obtaining an understanding of customers' imagery evaluation of product concepts and proposals. The progressive use of subjective evaluation, eye 
movement tests, and multi-dimensional image scale testing can be applied to the selection of preferred proposals by research subjects, and can also further highlight any corresponding positive and negative details. This therefore allows an intuitive description and explanation of why people might prefer a particular product, and provides a valuable reference for the evaluation of concepts. In addition, it provides the opportunity for designers to improve their schemes further.

The proposed method achieved good test results, demonstrating the effectiveness of the multi-dimensional and combined test methods. However, if the subjects intentionally conceal their opinions, inconsistencies may be found between the subjective and objective test results. Presently, the proposed method is unable to deal with the issue of analysing results when faced with inconsistencies, and an in-depth analysis of this issue is worthy of further research.

Many cross-disciplines have arisen from interaction and integration between disciplines. An example is cognitive neuroscience, a fusion of neuroscience and cognitive science, which has achieved rapid and significant development. Its use in functional magnetic resonance imaging, neurological image analysis, event-related electrical potentials, and other diagnostic tools has facilitated the use of visual images to observe the brain activities of subjects during and upon completion of cognitive tasks [34]. It has also been gradually applied to other fields, including consumer research and advertising. The multi-dimensional approach proposed in this study can make further use of these new techniques to directly test and objectively explain the psychologies of research subjects. The integration of new technical methods can prevent the occurrence of inconsistencies between two methods, and may even produce unanticipated results [35].

The introduction of an increasing variety of testing methods can lead to an increase in data volumes. There is, therefore, an urgent need for the study of data analysis approaches for use in data-rich conditions, such as visualisation and analysis methods for multi-dimensional time series data, so that the modes, characteristics, and trends hidden within the data can be understood, thereby facilitating the full use of the data [36].

\section{ACKNOWLEDGEMENT}

This research is supported by the Fundamental Research Funds for the Central Universities, NO. CDJ ZR13110042

\section{REFERENCES}

[1] Tseng, K.C. \& El-Ganzoury W. 2012. An intelligent system based on concurrent engineering for innovative product design at the conceptual design stage. Int. J. Adv. Manuf. Technol, 63, pp. 421-447.

[2] Huang, Q., Sun, S.Q., Sun, L.Y. \& Chai, C.L. 2005. Research on computer-aided industrial design technologies for product innovation. Hong Kong: International Academic Publishers Ltd.

[3] Lee, J.H. \& Chang, M.L. 2010. Stimulating designers' creativity based on a creative evolutionary system and collective intelligence in product design. Int. J. Ind. Ergon, 40, pp. 295-305.

[4] Turkka, K. \& Roope, T. 2010. Product concept design: A review of the conceptual design of products in industry. Springer.

[5] Schoormans, J.P.L., Ortt, R.J . \& Bont, C.J.P.M. 1995. Enhancing concept test validity by using expert consumers. J. Prod. Innov. Manage., 2(12), pp. 153-162.

[6] Berends, H., Reymen, I. Stultiens, R.G.L. \& Peutz, M. 2011. External designers in product design processes of small manufacturing firms, Design Stud, 32, pp. 86-108.

[7] Mahmood, M.A. \& Sullivan, G.L. 1992. Designing an expert consultation system to screen new product ideas - a consumer product application. Expert Syst. Appl, 5, pp. 87-101.

[8] Vanegas, L.V. \& Labib, A.W. 2005. Fuzzy approaches to evaluation in engineering design. J. Mech. Des., (Trans. ASME), 127, pp. 24-33.

[9] Ayag, Z. 2005. A fuzzy AHP-based simulation approach to concept evaluation in a NPD environment. IIE Trans, 37, pp. 827-842. 
[10] Evans, M., Wallace, D., Cheshire, D. \& Sener, B. 2005. An evaluation of haptic feedback modelling during industrial design practice. Design Stud., 26, pp. 487-508.

[11] Mugge, R., Govers, P.C.M. \& Schoormans, J.P.L. 2009. The development and testing of a product personality scale. Design Stud., 30, pp. 287-302.

[12] Sarkar, P. \& Chakrabarti, A. 2011. Assessing design creativity. Design Stud., 32, pp. 348-383.

[13] Hsiao, S.W., Hsu, C.F. \& Lee, Y.T. 2012. An online affordance evaluation model for product design. Design Stud., 33, pp. 126-159.

[14] Geng, X.L., Chu, X.N. \& Zhang, Z.F. 2009. Evaluation of product outline design scheme based on customer requirements satisfaction degree. J ournal of Shanghai J iaotong U., pp. 1923-1929.

[15] Xu, J ., Sun, S.Q. \& Zhang, K.J . 2007. Product image form optimization design based on fenetical algorithm. Chinese J ournal of Mechanical Engineering, pp. 53-58 +64.

[16] Rahman, O., Yan, J . \& Wing-Sun, L. 2008. Clothing evaluative criteria: A perspective of fashion design and consumers' aspirations. Hong Kong Polytechnic University, Kowloon.

[17] Roto, V., Vaananen-Vainio-Mattila, K., Law, E. \& Vermeeren, A. 2009. User experience evaluation methods in product development (UXEM'09). In: Gross, T., Gulliksen, J., Kotze, P., Oestreicher, L., Palanque, P., Prates, R. O. \& Winckler, M. (eds.) Human-Computer Interaction Interact 2009. Pt II, Proceedings, Berlin: Springer-Verlag Berlin, pp. 981-982.

[18] Hsu, S.H., Chuang, M.C. \& Chang, C.C. 2000. A semantic differential study of designers' and users' product form perception. Int. J. Ind. Ergon., 25, pp. 375-391.

[19] Bharadwaj, N., Nevin, J.R. \& Wallman, J.P. 2012. Explicating hearing the voice of the customer as a manifestation of customer focus and assessing its consequences. J. Prod. Innov. Manage., 29, pp. 1012-1030.

[20] Xu, Q.L., Jiao, R.J., Yang, X., Helander, M., Khalid, H.M. \& Opperud, A. 2009. An analytical Kano model for customer need analysis. Design Stud., 30, pp. 87-110.

[21] Miaskiewicz, T. \& Kozar, K.A. 2011. Personas and user-centered design: How can personas benefit product design processes? Design Stud., 32, pp. 417-430.

[22] Park, J. 2011. Developing a knowledge management system for storing and using the design knowledge acquired in the process of a user-centered design of the next generation information appliances. Design Stud., 32, pp. 482-513.

[23] Holsanova, J., Holmberg, N. \& Holmqvist, K. 2009. Reading information graphics: The role of spatial contiguity and dual attentional guidance. Appl. Cogn. Psychol., 23, pp. 1215-1226.

[24] J arodzka, H., Scheiter, K., Gerjets, P. \& van Gog, T. 2010. In the eyes of the beholder: How experts and novices interpret dynamic stimuli. Learn Instr., 20, pp. 146-154.

[25] Berg, M. \& Kojo, I. 2012. Integrating complex information with object displays: psychophysical evaluation of outlines. Behav. Inf. Technol., 31, pp. 155-169.

[26] Kukkonen, S. 2005. Exploring eye tracking in design evaluation, Joining Forces, Universityof Art and Design, Helsinki, pp. 119-126.

[27] Andrew, T.D. 2007. Eye tracking methodology: Theory and practice. Springer.

[28] Gregory, J.Z., Zhang, W., Yu, B., Cheny, X. \& Samaras, D. 2005. The role of top-down and bottom-up processes in guiding eye movements during visual search. Nineteenth Annual Conference on Neural Information Processing Systems, Canada.

[29] Nagamachi, M. 1995. Kansei engineering: An ergonomic technology for a product development. Proceedings of the 12th Triennial Congress of International Ergonomics Association, 4, pp. 120121.

[30] Nazlina, S. 2013. Methods of analyzing images based on Kansei engineering. International J ournal of Computer Science and Electronics Engineering (IJ CSEE), 1(3), pp. 417-421.

[31] Osgood, Ch.E., Suci, G.J. \& Tannenbaum P.H. 1967. The measurement of meaning. Univ. of Illinois.

[32] Lewis, J.R. 1992. Sample sizes for usability studies: Additional considerations (Tech. Report 54.711). Boca Raton, FL: International Business Machines Corp.

[33] Nielsen, J. 1994. Estimating the number of subjects needed for a thinking aloud test. Int. J. Hum. Comput. Stud., 41, pp. 385-397.

[34] Braeutigam, S. 2005. Neuroeconomics - From neural system to economic behavior. Brain Research Bulletin, 67, pp. 355-360.

[35] Hubert, M. \& Kenning, P. 2008. A current overview of consumer neuro-science. J ournal of Consumer Behavior, 7, pp. 272-292.

[36] Gennady, A. \& Natalia, A. (2005). Blending aggregation and selection: Adapting parallel coordinates for the visualization of large datasets. The Cartographic J ournal (S0008-7041), 42(1) 